\title{
Sutureless aortic valve replacement as an alternative treatment for patients belonging to the "gray zone" between transcatheter aortic valve implantation and conventional surgery: A propensity-matched, multicenter analysis
}

\author{
Augusto D'Onofrio, MD, ${ }^{\mathrm{a}}$ Antonio Messina, MD,${ }^{\mathrm{b}}$ Roberto Lorusso, MD, ${ }^{\mathrm{c}}$ Ottavio R. Alfieri, MD, ${ }^{\mathrm{d}}$ \\ Melissa Fusari, MD, ${ }^{\mathrm{e}}$ Paolo Rubino, MD, ${ }^{\mathrm{f}}$ Mauro Rinaldi, MD, ${ }^{\mathrm{g}}$ Roberto Di Bartolomeo, MD, \\ Mattia Glauber, MD, ${ }^{\mathrm{i}}$ Giovanni Troise, $\mathrm{MD},{ }^{\mathrm{b}}$ and Gino Gerosa, $\mathrm{MD}^{\mathrm{a}}$
}

\begin{abstract}
Objective: The aim of this propensity-matched, multicenter study was to compare early clinical and echocardiographic outcomes of patients undergoing transapical aortic valve implantation (TA-TAVI) versus patients undergoing sutureless aortic valve replacement (SU-AVR) for severe symptomatic aortic valve stenosis.
\end{abstract}

Methods: We reviewed 468 TA-TAVIs performed in 20 centers from April 2008 to May 2011, and 51 SUAVRs performed in 3 centers from March to September 2011. Based on a propensity score analysis, 2 groups with 38 matched pairs were created. Variables used in the propensity analysis were age, sex, body surface area, New York Heart Association class, logistic EuroSCORE, peripheral vascular disease, chronic obstructive pulmonary disease, aortic valve area, mitral regurgitation, and left ventricular ejection fraction.

Results: Preoperative characteristics of the 2 groups were comparable. Hospital mortality was $5.3 \%$ and $0 \%$ in the TA-TAVI and SU-AVR groups, respectively $(P=.49)$. We did not observe stroke or acute myocardial infarction in the 2 groups. Permanent pacemaker implantation was needed in 2 patients of each group $(5.3 \%$, $P=1.0)$. Dialysis was required in 2 patients $(5.3 \%)$ in the SU-AVR group and in 1 patient $(2.7 \%)$ in the TA-TAVI group $(P=1.0)$. Predischarge echocardiographic data showed that the incidence of paravalvular leak (at least mild) was greater in the TA-TAVI group ( $44.7 \%$ vs $15.8 \%, P=.001)$, but there were no differences in terms of mean transprosthetic gradient $(10.3 \pm 5 \mathrm{~mm} \mathrm{Hg}$ vs $11 \pm 3.7 \mathrm{~mm} \mathrm{Hg}, P=.59)$.

Conclusions: This preliminary experience showed that, in patients at high risk for conventional surgery, SUAVR is as safe and effective as TA-TAVI and that it is associated with a lower rate of postprocedural paravalvular leak. (J Thorac Cardiovasc Surg 2012;144:1010-8)

Surgical aortic valve replacement (SAVR) is the treatment of choice in patients with severe symptomatic aortic valve

\footnotetext{
From the Division of Cardiac Surgery, ${ }^{\text {a }}$ University of Padova, Padova, Italy; the Division of Cardiac Surgery, ${ }^{\mathrm{b}}$ Poliambulanza Hospital, Brescia, Italy; the Division of Cardiac Surgery, ${ }^{\mathrm{c}}$ Community Hospital, Brescia, Italy; the Department of Cardiac Surgery, ${ }^{\mathrm{d}}$ San Raffaele University Hospital, Milan, Italy; Department of Cardiovascular Sciences, ${ }^{\mathrm{e}}$ Centro Cardiologico Monzino, IRCCS, University of Milan, Milan, Italy; the Invasive Cardiology Laboratory, ${ }^{f}$ Cardiology Division, Montevergine Clinic, Mercogliano, Italy; the Division of Cardiac Surgery, ${ }^{\mathrm{g}}$ University of Turin, Turin, Italy; the Division of Cardiac Surgery, ${ }^{\mathrm{h}}$ University of Bologna, Bologna, Italy; and Department of Adult Cardiac Surgery, ${ }^{\mathrm{i}}$ G. Pasquinucci Heart Hospital, Massa, Italy.

Disclosures: Authors have nothing to disclose with regard to commercial support. Read at the 92nd Annual Meeting of The American Association for Thoracic Surgery, San Francisco, California, April 28-May 2, 2012.

A.O. and A.M. contributed equally to this manuscript.

Received for publication April 15, 2012; revisions received May 25, 2012; accepted for publication July 25, 2012; available ahead of print Sept 12, 2012.

Address for reprints: Augusto D'Onofrio, MD, Division of Cardiac Surgery, University of Padova, Centro Gallucci, Via Giustiniani 2, 35128 Padova, Italy (E-mail: adonofrio@hotmail.it).

$0022-5223 / \$ 36.00$

Copyright (c) 2012 by The American Association for Thoracic Surgery

http://dx.doi.org/10.1016/j.jtcvs.2012.07.040
}

stenosis (SSAVS) because it provides excellent early and long-term clinical outcomes as well as good results in terms of hemodynamics, valve durability, and freedom from valve-related complications. ${ }^{1}$ Transcatheter aortic valve implantation (TAVI) has shown excellent early and mid-term clinical and hemodynamic results in inoperable or highrisk patients with SSAVS., ${ }^{2,3}$ In particular, TAVI with balloon-expandable bioprostheses has demonstrated better results than medical therapy alone in inoperable patients ${ }^{4}$ as well as noninferiority to SAVR in high-risk elderly patients. ${ }^{5}$ TAVI using balloon-expandable valves can be accomplished with either an antegrade transapical access or with a retrograde approach. The latter is usually performed via a transfemoral access, but recently a transaortic approach has been described ${ }^{6,7}$; the transsubclavian access is used less frequently. The transfemoral access is generally considered the first choice because it is less invasive and there is no need for general anesthesia and tracheal intubation. However, transapical TAVI (TATAVI) provides good results with a low incidence of 


\section{Abbreviations and Acronyms \\ $\mathrm{CABG}=$ coronary artery bypass grafting \\ I-TA = Italian Registry of Trans-Apical Aortic Valve Implantation \\ NYHA $=$ New York Heart Association \\ SAVR = surgical aortic valve replacement \\ SSAVS = severe symptomatic aortic valve stenosis \\ SU-AVR $=$ sutureless aortic valve replacement \\ TA-TAVI $=$ transapical transcatheter aortic valve implantation \\ TAVI $=$ transcatheter aortic valve implantation}

access-related complications, even in patients with severe peripheral vascular disease. ${ }^{8}$ Recently, sutureless aortic valve replacement (SU-AVR) has been proposed as additional therapeutic option for the treatment of high-risk patients with SSAVS because it provides good early clinical and hemodynamic outcomes. ${ }^{9,10}$ Potential advantages of SU-AVR over SAVR are related mainly to the removal of the native aortic valve, to the shortening of aortic crossclamp time, and to the possibility of performing easier, minimally invasive access. Therefore, potential candidates for SU-AVR are high-risk, operable patients who could benefit from a shorter crossclamp time and/or from a minimally invasive procedure. In other words, they belong to a "gray zone" that includes patients who are at high risk for SAVR but who are not really inoperable. Because TAVI and SU-AVR are both aimed at the therapy of high-risk patients with SSAVS, the objective of this propensity-matched multicenter study is to compare clinical and echocardiographic outcomes at hospital discharge of patients undergoing TA-TAVI versus patients undergoing SU-AVR.

\section{PATIENTS AND METHODS}

This study was approved by the ethics committees, and patient informed consent was collected.

\section{Transapical Transcatheter Aortic Valve Implantation}

We reviewed data from 566 patients enrolled in the Italian Registry of Trans-Apical Aortic Valve Implantation (I-TA) from April 2008 through May 2011. The I-TA is an independent, prospective, multicenter registry that includes the majority of patients who have undergone TA-TAVI in Italy with the Edwards Sapien/Sapien XT pericardial bioprosthesis (Edwards Lifesciences, Irvine, Calif) since this procedure became available in April 2008. Details about the I-TA, participating centers and investigators, indications for TA-TAVI, device characteristics, sizing and surgical technique, postoperative medications, and data collection and analysis have been described previously. ${ }^{11}$ To avoid potential selection bias, we excluded from the current analysis 98 inoperable patients who underwent TA-TAVI for porcelain aorta. Consequently, we took into consideration the data from 468 patients in the I-TA who represent the unmatched TA-TAVI cohort of this study.

\section{Sutureless Valve}

We collected and analyzed data prospectively of 51 patients who underwent SU-AVR with the Perceval S bioprosthesis (Sorin Biomedica Cardio, Saluggia, Italy) at 3 Italian centers from March to September 2011. These patients represent the entire experience of the 3 participating institutions. Sutureless valve data were collected using the same data set of the I-TA to obtain homogeneous, comparable, and, most important, reliable data. The Perceval $\mathrm{S}$ is made of 3 bovine pericardium leaflets mounted on a self-expandable metallic stent. SU-AVR was performed with either full sternotomy, mini sternotomy or mini thoracotomy, according to the type of intervention, the associated procedures, and, ultimately, the surgeon's preferences. In particular, full sternotomy, mini sternotomy, and mini righ thoracotomy in the second intercostal space ${ }^{12}$ were performed in 36 (70.6\%), 4 (7.8\%), and 11 (21.6\%) patients, respectively. All SU-AVR procedures were performed under moderately hypothermic $\left(32^{\circ} \mathrm{C}\right)$ cardiopulmonary bypass with aortic crossclamping and cardioplegic arrest of the heart. A transverse aortotomy was performed around 3 to $3.5 \mathrm{~cm}$ above the aortic annulus, the native valve was removed, and annular decalcification was performed. Annular decalcification is not as extensive as for conventional surgery, but it is aimed at removing bulky calcifications to obtain a homogeneous, round-shaped annulus for sutureless valve implantation. After decalcification, the aortic annulus was sized and the correct prosthesis was selected. Prosthesis size "small" was selected, with an annulus diameter between $19 \mathrm{~mm}$ and $21 \mathrm{~mm}$. Size "medium" was selected, with an annulus diameter between $21 \mathrm{~mm}$ and $23 \mathrm{~mm}$. During the study period, size "large" was still not available. Three 4-0 prolene guiding sutures are passed through the aortic annulus at the nadir of each sinus. The delivery system was guided in its correct position using these sutures and the valve was deployed. After deployment, the delivery system and sutures were removed, and a balloon was inserted in the valve and expanded for 30 seconds at a pressure of $3 \mathrm{~atm}$. The ascending aorta was then closed according to the usual technique (Figure 1). Further details about Perceval S implantation technique have been described previously. ${ }^{9,13}$ Indications for SU-AVR were as follows: SSAVS defined by a valve area less than $0.8 \mathrm{~cm}^{2}$ and mean transaortic gradient more than $40 \mathrm{~mm} \mathrm{Hg}$, and a high surgical risk profile for advanced age ( $>75$ years), comorbidities, and patient frailty. Because there are no guidelines and/or recommendations for SU-AVR and experience is still limited, we did not use strict EuroSCORE or Society of Thoracic Surgeons score cutoff values as inclusion criteria. The decision to perform SU-AVR instead of SAVR or TAVI was made by the cardiac surgeon and was based mainly on a careful evaluation of the patient's preoperative characteristics and on clinical observation. Contraindications for the use of the Perceval $S$ valve were previous implantation of a valve prosthesis or annuloplasty ring not being replaced by the sutureless bioprosthesis, double- or multiple-valve surgery, aneurysmal dilatation $(\geq 45 \mathrm{~mm})$ or dissection of the ascending aorta, active endocarditis, bicuspid aortic valve, and recent myocardial infarction ( $<90$ days). A complete preoperative echocardiographic examination was performed in all patients to assess diameters of the aortic annulus, root, and sinotubular junction, and to measure the height of the aortic root (from the aortic annulus to the sinotubular junction). $\mathrm{Pa}$ tients were deemed suitable for a Perceval S implantation if the sinotubular junction diameter/annulus diameter ratio was $\leq 1.3$. Postoperatively, all patients with SU-AVR received aspirin $100 \mathrm{mg}$ daily, whereas patients with chronic atrial fibrillation received oral anticoagulation therapy.

Patients in both groups underwent clinical and echocardiographic assessment at the study site before the operation and at hospital discharge. Echocardiographic measurements were acquired according to current recommendations. ${ }^{14}$ Transvalvular pressure gradients were derived by using the modified Bernoulli equation. Prosthetic aortic regurgitation was classified as none or trace, mild $(1+/ 3+)$, moderate $(2+/ 3+)$, or severe $(3+/ 3+)$ according to recent recommendations. ${ }^{15}$ Preoperative risk factors were defined according to the EuroSCORE I classification, ${ }^{16}$ and postoperative outcomes were defined according to the Valve Academic Research Consortium definitions. ${ }^{17}$ 


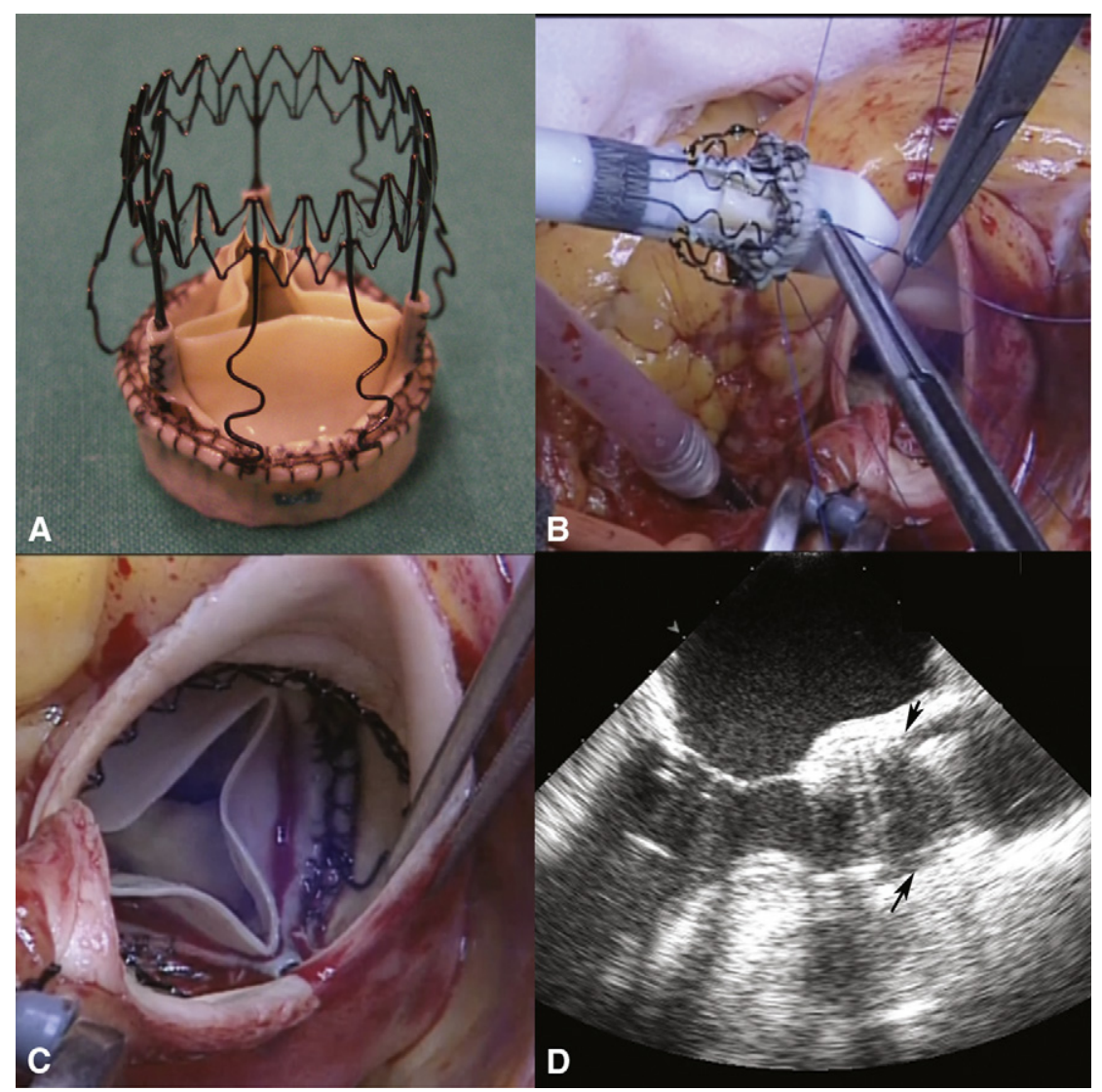

FIGURE 1. A, The Perceval S sutureless aortic bioprosthesis. The pericardial leaflets and the Nitinol frame are clearly visible. B, The bioprosthesis is collapsed on the holder. Three sutures are passed through a slot corresponding to the middle of each prosthetic leaflet and through the nadir of each native aortic sinus to allow for correct positioning of the valve. C, The valve is deployed in its correct position. D, Intraoperative transesophageal echocardiography showing the Perceval S (arrows) positioned correctly in the aortic annulus and in the aortic root.

\section{Statistical Analysis}

Continuous variables with a normal distribution are expressed as means \pm 1 standard deviation; those with a nonnormal distribution (assessed by the Shapiro-Wilk normality test) are presented as median and interquartile range ( $25 \%$ to $75 \%$ ). Categorical data are summarized by reporting absolute frequency distribution and percentage. Categorical variables were compared using the $\chi^{2}$-test or Fisher's exact test as appropriate. Student $t$ test (for unpaired data) or the Mann-Whitney test were used to compare continuous variables, as appropriate. Propensity score matching analysis was used to adjust for baseline characteristic differences between the 2 groups (1-to-1 matching based on propensity scores). The propensity score was estimated by a logistic regression model for each patient. Matching using calipers of width of 0.2 of the standard deviation of the logit of the propensity score was performed according to the suggestions of Austin. ${ }^{18}$ Variables used in the propensity analysis were age, sex, body surface area, New York Heart Association (NYHA) class, logistic EuroSCORE, peripheral vascular disease, chronic obstructive pulmonary disease, aortic valve area, mitral regurgitation, and left ventricular ejection fraction. The propensity c statistic was 0.96 . Comparisons between group outcomes were carried out by taking into consideration the matched nature of the propensity score-matched sample. In particular, the paired $t$-test or Wilcoxon's signed-rank test were used for continuous variables and the McNemar test was used for binary (dichotomous) variables. Statistical findings were considered significant if the critical level was less than $5 \%(P<.05)$. Statistical analysis was performed using
\end{abstract}

STATA software (release 10.0 for Windows; Stata Corporation LP, College Station, Tex).

\section{RESULTS}

Preoperative clinical and echocardiographic variables of the unmatched TA-TAVI (468 patients) and SU-AVR (51 patients) patient populations are listed in Table 1. In the unmatched cohort, TA-TAVI patients were more likely to have peripheral vascular disease and chronic obstructive pulmonary disease than SU-AVR patients. Furthermore, TA-TAVI patients had a significantly higher logistic EuroSCORE value, higher NYHA class, and lower left ventricular ejection fraction. After propensity analysis and matching, 2 groups of 38 patients each were created: the TA-TAVI group and the SU-AVR group. Preoperative clinical characteristics of the matched groups are listed in Table 2. The 2 groups were comparable in terms of preoperative characteristics. In particular, in TA-TAVI- and in SU-AVR-matched patients, the logistic EuroSCORE $(14.8 \pm 7.5 \%$ vs $13.7 \pm$ $7.2 \%, P=.47)$ and age $(80.9 \pm 6.9$ years vs $80.9 \pm 3.9$ years, $P=.92$ ) were similar, as well as NYHA functional 
TABLE 1. Preoperative data of the unmatched populations

\begin{tabular}{|c|c|c|c|}
\hline Variable & TA-TAVI $(n=468)$ & SU-AVR $(n=51)$ & $P$ Value \\
\hline Age, y (IR) & $82(78-86)$ & $80(76-83)$ & .007 \\
\hline Male sex, n (\%) & $190(40)$ & $6(12)$ & $<.001$ \\
\hline Hypertension, $\mathrm{n}(\%)$ & $374(79.9)$ & $37(72.6)$ & .21 \\
\hline Diabetes, $\mathrm{n}(\%)$ & $126(26.9)$ & $13(25.5)$ & .82 \\
\hline NYHA class $\geq 3, \mathrm{n}(\%)$ & $381(81.4)$ & $30(58.9)$ & $<.001$ \\
\hline Peripheral vascular disease, $\mathrm{n}(\%)$ & $180(38.4)$ & $5(9.8)$ & $<.001$ \\
\hline COPD, n $(\%)$ & $150(32.1)$ & $7(13.7)$ & .007 \\
\hline Neurologic dysfunction, $\mathrm{n}(\%)$ & $31(6.6)$ & $1(2)$ & .35 \\
\hline Dialysis, n (\%) & $6(1.3)$ & $1(2)$ & .51 \\
\hline Logistic EuroSCORE, \% & $26 \pm 14.4$ & $14.2 \pm 8.1$ & $<.001$ \\
\hline Coronary artery disease, $\mathrm{n}(\%)$ & $115(24.6)$ & $13(25.5)$ & .88 \\
\hline Previous cardiac surgery, $\mathrm{n}(\%)$ & $73(15.6)$ & $4(7.8)$ & .21 \\
\hline Atrial fibrillation, $\mathrm{n}(\%)$ & $98(21.3)$ & $6(11.8)$ & .14 \\
\hline LVEF, \% (IR) & $55(45-60)$ & $60(55-66)$ & .003 \\
\hline Mean transaortic gradient, $\mathrm{mm} \mathrm{Hg}$ (IR) & $51(41-60)$ & $47(42-54)$ & .17 \\
\hline Aortic valve area index, $\mathrm{cm}^{2} / \mathrm{m}^{2}$ (IR) & $0.50(0.40-0.69)$ & $0.47(0.40-0.59)$ & .03 \\
\hline Pulmonary artery pressure, $\mathrm{mm} \mathrm{Hg}$ (IR) & $44(35-55)$ & $40(34.5-45)$ & .01 \\
\hline
\end{tabular}

TA-TAVI, Transapical aortic valve implantation; SU-AVR, sutureless aortic valve replacement; $I R$, interquartile range; NYHA, New York Heart Association; COPD, chronic obstructive pulmonary disease; $L V E F$, left ventricular ejection fraction.

class, incidence of peripheral vascular disease, and incidence of chronic obstructive pulmonary disease. In the TA-TAVI group, prosthesis sizes of $23 \mathrm{~mm}$ and $26 \mathrm{~mm}$ were used in 16 patients $(42.1 \%)$ and 22 patients $(57.9 \%)$, respectively; in the SU-AVR group, size small and size medium were used in 17 patients $(44.7 \%)$ and 21 patients $(52.3 \%)$, respectively. In the SU-AVR group, 12 patients $(31.6 \%)$ underwent associated coronary artery bypass grafting (CABG) whereas in the TA-TAVI group, 10 patients $(26.3 \%)$ underwent coronary stenting pre-TAVI. Previous cardiac operations were performed in 3 patients $(7.9 \%)$ and in 5 patients $(13.2 \%)$ in the SU-AVR group
( 2 previous CABG and $1 \mathrm{SAVR}$ ) and in the TA-TAVI group (previous $\mathrm{CABG}$ in all 5 patients), respectively $(P=.71)$. In SU-AVR group, mean cardiopulmonary bypass time and aortic crossclamp time were $69 \pm 26$ minutes and $44 \pm$ 17 minutes, respectively, for isolated procedures, and 74 \pm 26 minutes and $50 \pm 20$ minutes, respectively, for the entire cohort. Postoperative outcomes are shown in Table 3. Hospital mortality occurred in 2 patients in the TA-TAVI group $(5.3 \%)$. Causes of hospital mortality were severe bleeding secondary to rupture of the aortic annulus and cardiogenic shock with multiorgan failure in 1 patient each. No hospital mortality occurred in the SU-AVR group $(P=.49)$.

TABLE 2. Preoperative characteristics of the two matched groups

\begin{tabular}{|c|c|c|c|}
\hline Variable & TA-TAVI $(\mathbf{n}=\mathbf{3 8})$ & SU-AVR $(n=38)$ & $P$ Value \\
\hline Age, y & $80.9 \pm 6.9$ & $80.9 \pm 3.9$ & .92 \\
\hline Male sex, n (\%) & $8(21.1)$ & $6(15.8)$ & .77 \\
\hline Hypertension, $\mathrm{n}(\%)$ & $31(81)$ & $28(74)$ & .58 \\
\hline Diabetes, $\mathrm{n}(\%)$ & $10(26)$ & $8(21)$ & .79 \\
\hline NYHA class $\geq 3, \mathrm{n}(\%)$ & $28(73.7)$ & $25(65.8)$ & .60 \\
\hline Peripheral vascular disease, $\mathrm{n}(\%)$ & $7(18.4)$ & $5(13.2)$ & .68 \\
\hline COPD, n $(\%)$ & $8(21.1)$ & $5(13.2)$ & .54 \\
\hline Neurologic dysfunction, $\mathrm{n}(\%)$ & $2(5)$ & $1(3)$ & 1.00 \\
\hline Dialysis, n (\%) & 0 & $1(3)$ & 1.00 \\
\hline Logistic EuroSCORE, \% & $14.8 \pm 7.5$ & $13.7 \pm 7.2$ & .47 \\
\hline Coronary artery disease, $\mathrm{n}(\%)$ & $17(45)$ & $13(34)$ & .45 \\
\hline Previous cardiac surgery, $\mathrm{n}(\%)$ & $5(13.2)$ & $3(7.9)$ & .71 \\
\hline Atrial fibrillation, $\mathrm{n}(\%)$ & $5(13.1)$ & $6(15.8)$ & 1.00 \\
\hline LVEF, \% (IR) & $60(55-65)$ & $60(55-65)$ & .99 \\
\hline Mean transaortic gradient, $\mathrm{mm} \mathrm{Hg}$ (IR) & $51.3 \pm 5.8$ & $48 \pm 9.1$ & .31 \\
\hline Aortic valve area index, $\mathrm{cm}^{2} / \mathrm{m}^{2}$ (IR) & $0.50(0.40-0.63)$ & $0.45(0.40-0.60)$ & .62 \\
\hline Pulmonary artery pressure, $\mathrm{mm} \mathrm{Hg}$ & $40.2 \pm 14.7$ & $39.5 \pm 9.6$ & .87 \\
\hline
\end{tabular}

TA-TAVI, Transapical aortic valve implantation; $S U$-AVR, sutureless aortic valve replacement; NYHA, New York Heart Association; COPD, chronic obstructive pulmonary disease; $L V E F$, left ventricular ejection fraction; $I R$, interquartile range. 
TABLE 3. Postoperative outcomes after TA-TAVI and SU-AVR

\begin{tabular}{|c|c|c|c|}
\hline Variable & TA-TAVI $(\mathbf{n}=38)$ & SU-AVR $(\mathbf{n}=38)$ & $P$ Value \\
\hline Hospital mortality, n (\%) & $2(5.3)$ & $0(0)$ & .49 \\
\hline ARF requiring $\mathrm{CVVH}, \mathrm{n}(\%)$ & $1(2.6)$ & $2(5.3)$ & 1.00 \\
\hline AMI, n $(\%)$ & $0(0)$ & $0(0)$ & 1.00 \\
\hline Stroke, n $(\%)$ & $0(0)$ & $0(0)$ & 1.00 \\
\hline Bleeding (life-threatening/disabling, major), $\mathrm{n}(\%)$ & $2(5.3)$ & $1(2.6)$ & 1.00 \\
\hline PPM implantation, $\mathrm{n}(\%)$ & $2(5.3)$ & $2(5.3)$ & 1.00 \\
\hline Mean transaortic gradient, $\mathrm{mm} \mathrm{Hg}$ & $10.25 \pm 5.03$ & $10.95 \pm 3.72$ & .59 \\
\hline $\mathrm{AR}$ at discharge (at least mild), $\mathrm{n}(\%)$ & $17(44.7)$ & $6(15.8)$ & .001 \\
\hline LVEF at discharge, $\%(\mathrm{IR})$ & $60(55-60)$ & $60(54-65)$ & .75 \\
\hline New-onset atrial fibrillation, $\mathrm{n}(\%)$ & $7(18.4)$ & $16(42.1)$ & .04 \\
\hline Orotracheal intubation time, hours (IR) & $4(0-5)$ & $5.5(4-8)$ & .21 \\
\hline
\end{tabular}

$T A-T A V I$, Transapical aortic valve implantation; $S U-A V R$, sutureless aortic valve replacement; $A R F$, acute renal failure; $C V V H$, continuous venovenous hemofiltration; $A M I$, acute myocardial infarction; $P P M$, permanent pacemaker; $A R$, aortic regurgitation; $L V E F$, left ventricular ejection fraction; $I R$, interquartile range.

Permanent pacemaker implantation was required in 2 patients $(5.3 \%)$ from each group $(P=1.00)$, whereas temporary renal replacement therapy with continuous venovenous hemofiltration was needed in 2 patients $(5.3 \%)$ in SU-AVR group and in 0 patients in the TA-TAVI group $(P=.49)$. Postoperative atrial fibrillation occurred in 16 patients $(42.1 \%)$ and in 7 patients $(18.4 \%)$ in the SU-AVR and TA-TAVI groups, respectively $(P=.04)$. We observed 1 life-threatening/disabling bleeding event (fatal bleeding) that caused patient death and 1 major bleeding in the TATAVI group (5.3\%), and 1 life-threatening/disabling bleeding event in the SU-AVR group $(2.6 \% ; P=1.00)$. Device success was $97.4 \%$ ( 37 of 38 patients; 1 patient needed a 2nd prosthesis for malposition) in the TA-TAVI group and $100 \%$ in the SU-AVR group $(P=1.00)$. Predischarge echocardiographic examination showed no differences in mean transprosthetic gradients (TA-TAVI: $10.25 \pm 5.03$ mm Hg vs SU-AVR: $10.95 \pm 3.72 \mathrm{~mm} \mathrm{Hg}, P=.59$ ), effective orifice area index (TA-TAVI: $1.1 \pm 0.21 \mathrm{~cm}^{2} / \mathrm{m}^{2}$ vs SUAVR: $\left.1.01 \pm 0.22 \mathrm{~cm}^{2} / \mathrm{m}^{2}, P=.64\right)$, and left ventricular ejection fraction between groups. On the other hand, we observed a significantly higher incidence of paravalvular leak (at least mild, $\geq 1+/ 3+$ ) in TA-TAVI patients (17 patients, $44.7 \%$ vs 6 patients, $15.8 \% ; P=.001)$. In particular, of the 17 TA-TAVI patients with paravalvular regurgitation, we observed a mild leak $(1+3+)$ in 14 patients and a moderate leak $(2+/ 3+)$ in 3 patients. Conversely, in the SU-AVR group, the observed paravalvular leak was always mild. We did not observe any stroke or acute myocardial infarction in the 2 groups.

\section{DISCUSSION}

During the past few years, many authors have investigated clinical and hemodynamic outcomes of TAVI, and yet few data exist regarding SU-AVR. To the best of our knowledge, this is the first study comparing TAVI and SU-AVR. In this study we examined 2 high-risk (age, $>80$ years; logistic EuroSCORE, $\sim 15 \%$ ), propensity-matched cohorts undergoing TA-TAVI or SU-AVR for SSAVS. We did not observe significant differences in hospital mortality, severe postoperative complications, and transprosthetic gradients between groups. However, we found a higher incidence of paravalvular leak in the TA-TAVI group and an increased rate of new-onset postoperative atrial fibrillation in the SU-AVR group. For every surgical technique, a correct selection of candidates is mandatory to achieve optimal results and, consequently, to improve patient outcome. With the introduction of sutureless aortic valve bioprostheses into clinical practice the portfolio of aortic valve substitutes can be considered complete. Patients with SSAVS can be scheduled for SAVR, TAVI, or SU-AVR according to their preoperative clinical features, anatomic characteristics, and risk profile. Although there is no doubt that nonelderly patients with a low surgical risk should undergo SAVR, and that very high-risk or inoperable patients could benefit from TAVI, the optimal treatment for high-risk operable patients is still controversial. In this analysis, among all TA-TAVI patients enrolled in the I-TA, propensity score and matching selected those with the lowest logistic EuroSCORE values. These patients have a high but not a very-high risk profile and belong to a "gray zone" where there is an overlap of indications for each treatment strategy; SAVR, TAVI, and SU-AVR are all potential therapeutic options. The decision-making process should be based on the characteristics of each substitute and on their advantages and disadvantages. SAVR remains the first choice for the treatment of SSAVS because it is well reproducible and offers optimal technical, clinical, and hemodynamic outcomes in the great majority of patients. The advantages of TAVI over SAVR are related mainly to its less invasiveness as a result of the absence of extracorporeal circulation and aortic crossclamping, the short duration of the procedure, and reduced surgical trauma. These features make TAVI a good option in inoperable ${ }^{4}$ or in very high-risk patients. ${ }^{5}$ On the other hand, SU-AVR requires extracorporeal circulation and aortic crossclamping, but their duration should, theoretically, 
be shorter than SAVR. Cardiopulmonary bypass and aortic crossclamping duration play a significant role in patient outcomes because they have been demonstrated to be independent predictors of 30-day postoperative mortality after adult cardiac surgery. ${ }^{19}$ Although, in our study, crossclamping and extracorporeal circulation were similar to those reported in the literature for conventional $\mathrm{SAVR},{ }^{20}$ it has been shown that, in isolated SU-AVR, mean aortic clamp time can be as low as 18 minutes, ${ }^{9}$ which is most likely related to the learning curve and to surgical experience. Furthermore, our series included patients who were operated on through minimally invasive approaches (mini sternotomy and mini right thoracotomy) that may require longer crossclamp times, especially when new technologies are used. High-risk patients undergoing associated procedures are those who probably benefit most from the reduction of crossclamp and cardiopulmonary bypass time. In our matched cohort, one third of SU-AVR patients underwent associated CABG, and $20 \%$ of TA-TAVI patients underwent coronary stenting prior to the aortic valve procedure, without any postoperative acute myocardial infarction in the 2 groups. Thus, we can speculate that among high-risk patients with combined coronary artery disease and SSAVS, those with percutaneous coronary intervention-eligible coronary artery lesions can be selected for staged PCI and TAVI whereas those deemed untreatable with PCI can be scheduled for SU-AVR and associated CABG. Larger prospective studies are needed to confirm this inference.

Although TAVI represents a well-established technique for the treatment of SSAVS, it is associated with a noticeable rate of paravalvular leak. In our TA-TAVI matched population, a significant paravalvular leak (at least mild, $\geq 1+3+$ ) was found in 17 patients $(44.7 \%)$; in particular, a mild leak and a moderate leak were found in 14 and in 3 patients, respectively. A significantly lower incidence of paravalvular aortic regurgitation was observed in the SU-AVR population (6 patients with a mild leak, $15.8 \%, P=.001$ ). A recently published update of the Placement of Aortic Transcatheter Valve (PARTNER) trial shows that the incidence of paravalvular leak is significantly higher after TAVI than after SAVR at both 1 year and 2 years. ${ }^{21}$ Paravalvular leak has a major impact on patient outcome; in fact, in the PARTNER trial, the presence of paravalvular aortic regurgitation after TAVI was associated with an increased rate of late mortality, the effect of aortic regurgitation on mortality was proportional to the severity of regurgitation, and even mild aortic regurgitation was associated with an increased rate of late deaths. ${ }^{21}$ Furthermore, postprocedural paravalvular leak was identified as an independent predictor of late mortality after TAVI (hazard ratio, 3.79). ${ }^{22,23}$ In this scenario, the finding of a low paravalvular leak rate after SU-AVR is of great importance during the decision-making process for the choice of the valve substitute. The incidence of mild $(1+3+)$ paravalvular leak in the sutureless group found in this study $(15 \%)$ was similar to that reported in another series 9 and should be considered acceptable because this was an initial experience with all the learning curve-related issues. In fact, there are still many things to learn in terms of patient selection, prosthesis sizing, positioning, and annular decalcification. We are not surprised by the higher incidence of postoperative atrial fibrillation in the SU-AVR group because this procedure is a true open-heart surgery. The occurrence of atrial fibrillation after cardiac surgery is associated with important complications, such as cognitive changes, renal dysfunction, and infection, ${ }^{24}$ that in a high-risk population may have a significant impact on patient outcomes.

This study has several limitations. The analysis was performed on a small number of patients and only on hospital outcomes. The small number of matched pairs derives from the relatively small general SU-AVR population (51 patients) and from the covariates selected for matching, which led to the creation of 2 perfectly matched groups (c statistic, 0.96) including 38 patients each. TATAVI surgery was started before SU-AVR and, consequently, for some patient the 2 options were not available. However, definitive patient selection was always made after multidisciplinary discussion. Echocardiographic examinations were performed by different physicians using different machines, and we did not have a central echo core lab. Adverse events were assigned by each center and were not reviewed by an ad hoc committee. To give a correct interpretation of these data we must highlight that (1) we considered only TA-TAVI and (2) both Sapien and Sapien XT were included. The decision to include transapical patients only was based mainly on the impossibility of collecting data from all Sapien-Italian transfemoral patients, because a specific registry of this kind does not exist. Because most TAVI programs are based on a transfemoral-first policy, TA-TAVI patients generally have a higher risk profile than transfemoral patients, ${ }^{25} \mathrm{al}-$ though no significant differences in outcomes have been observed. ${ }^{26}$ Sapien and Sapien XT have a different incidence of paravalvular leak because of their slightly different design. Furthermore, the Sapien valve was used during our early experience when the learning curve, especially regarding sizing and positioning, was new. This was a preliminary experience; further larger and possibly prospective, randomized studies that include all TAVI approaches are needed to confirm these results and to evaluate medium- and long-term outcomes in terms of survival, device durability, and freedom from valve-related adverse events.

In conclusion, our data suggest that SU-AVR is as safe and effective as TA-TAVI in high-risk patients with SSAVS. 
SU-AVR is associated with a lower incidence of paravalvular leak but with a higher incidence of postoperative atrial fibrillation. A center that has the ability to perform SAVR, TAVI (with all its approaches), and SU-AVR is able to offer the full spectrum of available therapeutic options for SSAVS and, consequently, can choose the best treatment for each patient, according to his or her specific clinical and anatomic features.

The authors are sincerely grateful to Marco De Franceschi, BSc, for his generous support in data review, statistical analysis, and manuscript review.

\section{References}

1. Valfrè C, Ius P, Minniti G, Salvador L, Bottio T, Cesari F, et al. The fate of Hancock II porcine valve recipients 25 years after implant. Eur J Cardiothorac Surg. 2010;38:141-6.

2. Thomas M, Schymik G, Walther T, Himbert D, Lefèvre T, Treede H, et al. Oneyear outcomes of cohort 1 in the Edwards SAPIEN Aortic Bioprosthesis European Outcome (SOURCE) registry: the European registry of transcatheter aortic valve implantation using the Edwards SAPIEN valve. Circulation. 2011;124: 425-33.

3. Rodés-Cabau J, Webb JG, Cheung A, Ye J, Dumont E, Feindel CM, et al. Transcatheter aortic valve implantation for the treatment of severe symptomatic aortic stenosis in patients at very high or prohibitive surgical risk: acute and late outcomes of the multicenter Canadian experience. J Am Coll Cardiol. 2010;55: 1080-90.

4. Leon MB, Smith CR, Mack M, Miller DC, Moses JW, Svensson LG, et al. Transcatheter aortic valve implantation in patients who cannot undergo surgery. N Engl J Med. 2010;363:1597-607.

5. Smith CR, Leon MB, Mack MJ, Miller DC, Moses JW, Svensson LG, et al. Transcatheter versus surgical aortic-valve replacement in high-risk patients. N Engl J Med. 2011;364:2187-98.

6. Gerosa G, Fabozzo A, Bianco R, Tarantini G, D’Onofrio A. Transaortic balloonexpandable aortic valve implantation. J Thorac Cardiovasc Surg. December 15, 2011; http://dx.doi.org/10.1016/j.jtcvs.2011.12.005 [Epub ahead of print].

7. Bapat V, Khawaja MZ, Attia R, Narayana A, Wilson K, Macgillivray K, et al. Transaortic transcatheter aortic valve implantation using Edwards Sapien valve: a novel approach. Catheter Cardiovasc Interv. 2012;79:733-40.

8. D'Onofrio A, Fusari M, Abbiate N, Zanchettin C, Bianco R, Fabbri A, et al. Transapical aortic valve implantation in high-risk patients with severe aortic valve stenosis. Ann Thorac Surg. 2011;92:1671-7.

9. Flameng W, Herregods MC, Hermans H, Van der Mieren G, Vercalsteren M, Poortmans G, et al. Effect of sutureless implantation of the Perceval S aortic valve bioprosthesis on intraoperative and early postoperative outcomes. J Thorac Cardiovasc Surg. 2011;142:1453-7.

10. Martens S, Sadowski J, Eckstein FS, Bartus K, Kapelak B, Sievers HH, et al. Clinical experience with the ATS $3 \mathrm{f}$ enable sutureless bioprosthesis. Eur J Cardiothorac Surg. 2011;40:749-55.

11. D'Onofrio A, Rubino P, Fusari M, Salvador L, Musumeci F, Rinaldi M, et al. Clinical and hemodynamic outcomes of "all-comers" undergoing transapical aortic valve implantation: results from the Italian Registry of Trans-Apical Aortic Valve Implantation (I-TA). J Thorac Cardiovasc Surg. 2011;142:768-75.

12. Glauber M, Miceli A, Bevilacqua S, Farneti PA. Minimally invasive aortic valve replacement via right anterior minithoracotomy: early outcomes and midterm follow-up. J Thorac Cardiovasc Surg. 2011;142:1577-9.

13. Shrestha M, Folliguet T, Meuris B, Dibie A, Bara C, Herregods MC, et al. Sutureless Perceval S aortic valve replacement: a multicenter, prospective pilot trial. J Heart Valve Dis. 2009;18:698-702.

14. Lang RM, Bierig M, Devereux RB, Flachskampf FA, Foster E, Pellikka PA, et al. Recommendations for chamber quantification. Eur J Echocardiogr. 2006;7: 79-108.

15. Zoghbi WA, Chambers JB, Dumesnil JG, Foster E, Gottdiener JS, Grayburn PA, et al. Recommendations for evaluation of prosthetic valves with echocardiography and Doppler ultrasound: a report from the American Society of Echocardiography's Guidelines and Standards Committee and the Task Force on Prosthetic Valves, developed in conjunction with the American College of Car- diology Cardiovascular Imaging Committee, Cardiac Imaging Committee of the American Heart Association, the European Association of Echocardiography, a registered branch of the European Society of Cardiology, the Japanese Society of Echocardiography and the Canadian Society of Echocardiography, endorsed by the American College of Cardiology Foundation, American Heart Association, European Association of Echocardiography, a registered branch of the European Society of Cardiology, the Japanese Society of Echocardiography, and Canadian Society of Echocardiography. J Am Soc Echocardiogr. 2009;22: 975-1014.

16. Nashef SA, Roques F, Michel P, Gauducheau E, Lemeshow S, Salamon R. European system for cardiac operative risk evaluation. Eur J Cardiothorac Surg. 1999;16:9-13.

17. Leon MB, Piazza N, Nikolsky E, Blackstone EH, Cutlip DE, Kappetein AP, et al. Standardized endpoint definitions for transcatheter aortic valve implantation clinical trials. J Am Coll Cardiol. 2011;57:253-69.

18. Austin PC. Propensity-score matching in the cardiovascular surgery literature from 2004 to 2006: a systematic review and suggestions for improvement. J Thorac Cardiovasc Surg. 2007;134:1128-35.

19. Nissinen J, Biancari F, Wistbacka JO, Peltola T, Loponen P, Tarkiainen P, et al. Safe time limits of aortic cross-clamping and cardiopulmonary bypass in adult cardiac surgery. Perfusion. 2009;24:297-305.

20. Brown ML, Pellikka PA, Schaff HV, Scott CG, Mullany CJ, Sundt TM, et al. The benefits of early valve replacement in asymptomatic patients with severe aortic stenosis. J Thorac Cardiovasc Surg. 2008;135:308-15.

21. Kodali SK, Williams MR, Smith CR, Svensson LG, Webb JG, Makkar RR, et al. Two-year outcomes after transcatheter or surgical aortic-valve replacement. N Engl J Med. 2012;366:1686-95.

22. Tamburino C, Capodanno D, Ramondo A, Petronio AS, Ettori F, Santoro G, et al. Incidence and predictors of early and late mortality after transcatheter aortic valve implantation in 663 patients with severe aortic stenosis. Circulation. 2011;123:299-308.

23. Sinning JM, Hammerstingl C, Vasa-Nicotera M, Adenauer V, Lema Cachiguango SJ, Scheer AC, et al. Aortic regurgitation index defines severity of peri-prosthetic regurgitation and predicts outcome in patients after transcatheter aortic valve implantation. J Am Coll Cardiol. 2012;59:1134-41.

24. Mathew JP, Fontes ML, Tudor IC, Ramsay J, Duke P, Mazer CD, et al. A multicenter risk index for atrial fibrillation after cardiac surgery. JAMA. 2004;291:1720-9.

25. Bleiziffer S, Ruge H, Mazzitelli D, Hutter A, Opitz A, Bauernschmitt R, et al. Survival after transapical and transfemoral aortic valve implantation: talking about two different patient populations. J Thorac Cardiovasc Surg. 2009;138:1073-80.

26. Johansson M, Nozohoor S, Kimblad PO, Harnek J, Olivecrona GK, Sjögren J. Transapical versus transfemoral aortic valve implantation: a comparison of survival and safety. Ann Thorac Surg. 2011;91:57-63.

\section{Discussion}

Dr Thierry P. Carrel (Berne, Switzerland). Thank you very much for the privilege of discussing this paper. The portfolio of aortic valve replacement has recently been extended by several sutureless aortic valve prostheses that have been introduced on the European market in recent years, but there is no clear-cut indication for these new types of valves so far. They are all restricted to the treatment of a stenotic aortic valve, and the main advantage claimed by the manufacturers is the reduction of the aortic crossclamp time. Some recent studies on very limited patient populations seem to confirm these findings so far.

In isolated aortic valve replacement, the crossclamp time is the major determinant of cardiopulmonary bypass duration, but less evidence exists of the role of the crossclamp time in affecting the outcome neither in the general cardiac population nor in the specific population treated for isolated aortic valve stenosis. No study so far has addressed the selection of patients at particular benefit for a significant reduction in crossclamp time for aortic valve stenosis.

So the current study, although it addresses only certain interesting aspects of aortic valve replacement, is a timely, nice study 
because it has become more and more critical to determine which procedure is the optimal one to treat aortic valve stenosis on an individual case-by-case appreciation. And the most interesting message is that the incidence and severity of paravalvular leakage was higher in the TAVI group than in the surgical group, although $15 \%$ of paravalvular leakage is still not acceptable for a surgical procedure!

So I have three questions for the authors. Could you give a short comment on the learning curve to feel comfortable when using a sutureless valve, and which surgical access do you consider to be the best one for a sutureless valve implantation? Frankly speaking, I found 44 minutes still a long crossclamp time for isolated sutureless valve implantation, and I ask this question because we have found sutureless valve implantation through a less-invasive approach to be somewhat cumbersome as long as the introducing devices for these valves are not flexible enough to permit easy deployment under perfect visualization.

Second question: A large majority of TAVI procedures are performed through a transfemoral approach worldwide. Why did you select only the transapical approach as a comparison group when the sutureless valves may well address also those patients scheduled for a transfemoral approach?

And finally, I would like to question the size of the aortic annulus. Because TAVI was available for sizes 23 and 26, but sutureless valves only for sizes 21 and 23, do you think that the absence of difference in the pressure gradients seen in the postoperative echo between these 2 valves is a result of the fact that large sizes were implanted only in TAVI and smaller sizes in sutureless valves? I would expect sutureless performing much better than TAVI, because the valve can be excised during a sutureless valve procedure.

Thank you very much again.

Dr D'Onofrio. Dr Carrel, thank you for your questions. The learning curve of sutureless aortic valve implantation is less demanding than the learning curve for TAVI, especially for cardiac surgeons, who are more used to a surgical approach than to a catheter-based approach.

Crossclamp time in this series for isolated valve replacement was 44 minutes, but in the literature it has been shown that the crossclamp time can be as low as 18 minutes. I believe that this difference is mainly a result of the learning curve and the fact that these were the very first cases that we have done in Italy. Regardless, we observe that, as experience increases, the crossclamp times reduce progressively. So I am pretty sure that, in future studies, we will show shorter crossclamp times.

The great majority of centers that participate to the Italian Transapical registry, called ITA, are based on a transfemoral-first approach. Our registry includes only transapical procedures, and for this study we didn't have the possibility to retrieve transfemoral data as well. However, because transfemoral procedures are performed mainly by interventional cardiologists, in this study we observed cardiac surgeons performing both transcatheter and surgical procedures, and this is quite interesting.

There were no differences in terms of gradients between transapical and sutureless valves. It is a very small series, so I don't think we can draw any final conclusion from this study. Actually, I don't think that label size has a big importance regarding transvalvular gradients.
I hope I answered all your questions.

Dr Joseph F. Sabik (Cleveland, Ohio). I have a question about the technical aspects of deploying the sutureless valves. How aggressive do you debride the calcium in the aortic annulus? Do you want some calcium left behind to hold the valve in placelet's just say like a transcatheter valve-or do you want to debride it aggressively like we would do in an open procedure?

Dr D'Onofrio. We take the calcium away from the annulus, but it is not important to take away everything as for conventional valves. We just want to have a homogenous, round-shaped annulus even with some calcium, so that the valve can be implanted smoothly.

Dr Sabik. Does debridement influence whether you have any leakage around the valve?

Dr D'Onofrio. Sorry?

Dr Sabik. How aggressively you debride, does that influence the leakage around the valve, if there is any, any paravalvular aortic insufficiency?

Dr D'Onofrio. Yes, we observed a small incidence of paravalvular leak in sutureless valves. The most important thing is to have a round-shaped homogeneous debridement without bulky pieces of calcium in the annulus before sutureless valve implantation. We did not observe a relationship between the extension of annular decalcification and paravalvular leak.

Dr Khaled D. Algarni (Toronto, Ontario, Canada). You have done a very good job trying to match these 2 groups; however, frailty is an important confounder that you perhaps haven't accounted for. Do you think that in the TAVI group there were more patients who were frail than in the sutureless valve group? And that might explain the higher mortality in the TAVI group?

Dr D'Onofrio. Of course, frailty is important, but we didn't collect specific data about this aspect, so we were not able to include any frailty index as a variable into the statistical analysis. The logistic EuroSCORE of the matched TAVI population was lower than the logistic EuroSCORE of the entire TAVI cohort. This is because propensity matching selected patients with a low logistic EuroSCORE. And the indication of these patients for TAVI was based mainly on frailty, rather than on EuroSCORE, but unfortunately we don't have a numeric value for that.

Dr Mustafa Cikirikcioglu (Geneva, Switzerland). First of all, I congratulate the authors for a timely report on sutureless aortic valves. My question is concerning the paravalvular leak rate. You announced $15 \%$ of paravalvular leak for the Perceval group. Do you think this is an acceptable percentage for a surgical aortic valve replacement group? And my second question: Why did you not choose a third group of patients that would include only surgically and standard aortic valve replacement? Thank you.

Dr D'Onofrio. I want to answer your second question first. We are now designing a new study considering all 3 groups-transcatheter, sutureless, and surgical aortic valve. I hope it will be done in the very near future.

Dr Cikirikcioglu. And, in your opinion, is it acceptable?

Dr D'Onofrio. We have to consider that this is just a very preliminary and a very initial experience, so there is a learning curve. The leaks were always mild, and I think that in the future the incidence of paravalvular leak will go down for sure. It is like transcatheter valves; we are now learning how to make sizing, how to make deployment. We are learning a lot of things, and I think 
that for sutureless valves it will be exactly the same. After the learning curve, I believe that results will improve.

Dr Keith B. Allen (Kansas City, Mo). I want to follow up on that last question. We know from recent PARTNER data that even mild paravalvular leak has a negative impact on mortality. You may not have known that when you were doing this study but, moving forward, is that knowledge going to change how you will use the sutureless valve? Because you have the patient open and on bypass, and putting in some type of a sewn-in valve may only add 10 or 15 minutes to the operation without the complication of paravalvular leaks?

Dr D'Onofrio. Yes, I totally agree with you. Paravalvular leak is a very important determinant of early and late results in aortic valve patients, and I think that with sutureless valves we just have to identify who are the right patients who need this procedure. And for this reason, I think we have to find a compromise and to accept a low rate of paravalvular leak. However, as I said before, with the learning curve and with experience I think that our results will improve for sure.

Dr Behzad Soleimani (Hershey, $\mathrm{Pa}$ ). Thank you for your clear presentation. I have a question again on the paravalvular leak in the sutureless group. How many of the paravalvular leaks were detected at the end of the procedure with on-table transesophageal echocardiogram (TEE)? And second, if you had more than mild AI, what would have been your strategy in the operating room?

Dr D'Onofrio. Four of these minor leaks were found at predischarge examination, and only 2 were found on the intraoperative TEE. We decided not to touch these minor leaks, because the procedure was really complex and it would have been worse to clamp the aorta again to fix just a minor leak. In case a moderate leak is found, the behavior is similar to conventional aortic valve replacement. If we find a moderate leak, we go on pump again, we clamp the aorta, and we fix it. 